\title{
Continuous Production of Melamine-Formaldehyde Microcapsules Using a Mesostructured Reactor
}

\author{
Ana C. G. Moreira, Yaidelin A. Manrique, Isabel M. Martins, Isabel P. Fernandes, Alírio E. Rodrigues,
} José C. B. Lopes, and Madalena M. Dias*

Cite This: Ind. Eng. Chem. Res. 2020, 59, 18510-18519

Read Online

\section{ACCESS I}

亗 Metrics \& More

回 Article Recommendations

ABSTRACT: A mesostructured NETmix reactor was adapted to develop a continuous process to produce microcapsules, focusing on the steps commonly used in batch formulation: the emulsion and cure. Microcapsules were formed through a polycondensation process by coating Miglyol, a skin-hydrating emollient, with melamine-formaldehyde, which is a resistant shell material with surface smoothness. Different recirculation times were tested for the cure step. Microcapsules show a spherical shape and smooth membrane. Efficiencies of encapsulation of $75 \%$, core contents of $70 \%$, and diameters around $20 \mu \mathrm{m}$, ideal range for textile impregnation, were obtained. Scanning electron microscopy shows the integrity of microcapsules on textiles after impregnation and their flexible behavior. The thermogravimetric analysis confirmed the thermal stability of microcapsules up to $210^{\circ} \mathrm{C}$. With the NETmix reactor, it is possible to reduce the cure time of traditional batch formulation in $80 \%$, producing microcapsules with similar characteristics in a continuous process.

\section{INTRODUCTION}

Microencapsulation involves coating of an active ingredient by a membrane of another material. ${ }^{1}$ The core of microcapsules is the active principle, which is responsible for its functionalization and, depending on its characteristics, the respective application. The external material, the shell, covers the core, providing protection against external factors and stability of the active principle and masking unwanted properties such as odor or taste. ${ }^{2}$ These properties can be a great advantage and benefit depending on the final application. Food, ${ }^{3,4}$ medicine, ${ }^{5,6}$ agriculture, ${ }^{7}$ cosmetics, ${ }^{8,9}$ or textile industries ${ }^{10-14}$ are some examples of areas of interest. The textile industry is an important area of interest for microencapsulation since functionalized textiles promote comfort and protection. According to Devan Chemicals, fabrics can be divided into four markets, bed and bath, home, clothing, and mobility, ${ }^{15}$ and in all cases, the functionalized fabrics must have the same characteristics as a nontreated fabric, for example, a soft touch or the visual effect of the fabric. The encapsulated active principle is chosen based on the characteristics that are responsible for the fabrics' functionalization. Antibacterial materials such as vitamins ${ }^{16,17}$ are encapsulated to avoid the growth of microorganisms and fungi in bed clothes or ligatures. ${ }^{18}$ Carrier oils such as triglycerides are non-irritating skin emollients ${ }^{19}$ with excellent skin absorption ${ }^{20}$ and are encapsulated due to their skin-hydrating properties. These active principles are marketed in fabrics, which can be used for long contact periods with skin, such as cosmetic textiles. ${ }^{21}$

There are several methods of microencapsulation, but in most cases, with common steps such as preparation of aqueous and organic solutions, ${ }^{10,22,23}$ emulsification, ${ }^{1,11,22,24-26}$ curing, ${ }^{10,27}$ and/or solidification/hardening of microcapsules. $1,11,24,25$

Emulsification, with the formation of a stable emulsion, is the key step in microencapsulation since the diameter of oily droplets defines the diameter of the microcapsules. ${ }^{28}$ A good emulsion promotes the stability of droplets during the entire process.

Droplet size control is particularly difficult when the emulsification process is scaled from laboratory to industrial scale, commonly polydisperse origination emulsions. ${ }^{28-30}$ Furthermore, in batch processes, care must be taken to obtain a homogeneous and stable emulsion to produce microcapsules with consistent properties in terms of morphology, diameter, and encapsulation efficiency. ${ }^{31}$ Different types of stirring

Received: May 28, 2020

Revised: September 14, 2020

Accepted: September 16, 2020

Published: September 16, 2020 
systems are often used at laboratory scale, such as mechanical stirrers, ultrasonic mixers, and homogenizers. To obtain a good mixture, various types of stirring systems can be used, and it must be ensured that conditions such as the power of the stirrer, the stirrer velocity, or its positioning promote mixing through the whole volume of the vessel. ${ }^{28,32}$

Interfacial polycondensation and in situ polymerization are some of the chemical methods used to produce microcapsules with melamine resin as a wall material. These procedures require a step of prepolymer formation, where monomers are added in a solution, and then a cure of prepolymer around the oily droplets is taken by increasing the temperature. ${ }^{32}$ Usually, traditional batch methods to produce melamine-based microcapsules present the main disadvantage of long (around $4 \mathrm{~h}$ ) duration procedures, where the cure step takes 2 to $3 h^{22,33-35}$

In the past few years, nonconventional techniques, such as microfluidic devices, have gained attention to produce emulsions and microcapsules in continuous mode. Different geometries of microfluidic capillaries such as coflow, ${ }^{36,37}$ flowfocusing, ${ }^{37,38}$ and $\mathrm{T}$-junction and their variants (cross section or V-junction $)^{39,40}$ have been used. Some advantages of this technique are the combinations of different geometries in the different steps of the microencapsulation process ${ }^{41,42}$ and the production of droplets of high control of internal morphology. ${ }^{43}$ However, this technique is mostly used at laboratory scale and due to the high cost for manufacturing of the microfluidic devices. These high costs are due to the complex fabrication of miniaturized units, requiring special operation procedures and specially trained researchers. ${ }^{44}$ Additionally, one of the most used materials to fabricate the microfluidic capillaries (polydimethylsiloxane) has limitations, such as working at high temperatures and chemical incompatibility with organic solvents. ${ }^{44,45}$

The main goal of this work was to produce microcapsules in continuous mode using a NETmix technology, creating a stable oil-in-water emulsion and reducing the operation time of the cure step. The mesostructured reactor NETmix is a patented technology ${ }^{46}$ developed at LSRE-LCM, and it consists of a network of interconnected chambers and channels (Figure 1a), where chambers operate as mixing zones and

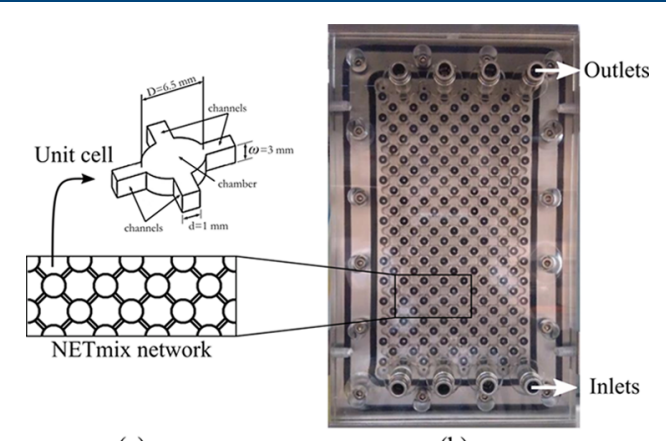

(a)

(b)

Figure 1. (a) Schemes of NETmix network and unit cell and (b) prototype of Lab-scale NETmix 2D.

channels behave as a plug flow. Above a critical Reynolds number of 150, this system evolves to a self-sustained oscillatory laminar flow regime, inducing local strong laminar mixing. ${ }^{47-49}$ This technology applied to microencapsulation allows an effective reactant distribution promoting a good emulsification step, controlling the reactant flow, and decreasing the time of procedure. ${ }^{48}$ Another advantage of
NETmix is that different injection schemes may be used by feeding the reactants to different inlet channels. A continuous process for the production of highly pure, synthetic nanocrystalline hydroxyapatite using NETmix was developed and implemented at the industrial level (https://www.fluidinova. com/ $).^{50,51}$ Other applications using NETmix include the production of nanohydroxyapatite/chitosan dispersions and photocatalysis processes. ${ }^{52,53}$

A NETmix prototype, the Lab-scale NETmix 2D (Figure 1b) with geometry and characteristics described by Fonte et al., ${ }^{54}$ was used to produce a stable oil-in-water emulsion and to cure the membrane of the microcapsules. This NETmix reactor consists of a network of 29 rows and 8 columns of cylindrical chambers with a diameter $(D)$ of $6.5 \mathrm{~mm}$ and depth $(\omega)$ of 3 $\mathrm{mm}$. The prismatic channels have a width $(d)$ of $1 \mathrm{~mm}$ and the total volume of the reactor is $23 \mathrm{~mL}$.

Commercial melamine-formaldehyde capsules were chosen as a case study for a project in collaboration with Devan Chemicals, who provided the reactants and batch formulation. Melamine-formaldehyde is used as a shell material due to several advantages such as good resistance against water and heat, protecting the core, high hardness and mechanical robustness, and surface smoothness, which is a benefit for textile applications. ${ }^{22,27,55}$ According to Devan Chemicals, in these capsules, a methylated melamine resin, with a low level of formaldehyde, is used, as well as formaldehyde quenchers, resulting in microcapsule slurries with 200-300 ppm formaldehyde. When this type of product is applied in fabrics, the levels of formaldehyde are below $75 \mathrm{ppm}$, which enables its use in underwear clothing fabrics, and, in many cases, below 16 ppm, suitable for use in fabrics for babywear.

Miglyol, a carrier oil, was used as a core material due to its characteristics of skin-hydrating agents and proper skin absorption. $^{20}$ Furthermore, this caprylic/capric triglyceride has an excellent emollience and is a good carrier material for encapsulated substances that require oxidative and physical stability, such as vitamins. ${ }^{20,56}$ Oily droplets were encapsulated by melamine-formaldehyde through an interfacial polycondensation process. The produced microcapsules were impregnated by the padding process for the purpose of obtaining functionalized textiles. Microcapsules were characterized by optical microscopy (OM) and scanning electronic microscopy (SEM) to evaluate morphology and size. Particle size distribution, solid and core content, encapsulation efficiencies, and shell thickness were also evaluated. Thermal stability was accessed by thermogravimetric analysis. Microcapsules impregnated in textiles were observed with SEM.

\section{MATERIALS AND METHODS}

2.1. Materials. A melamine-formaldehyde prepolymer and Miglyol 812 were used respectively as the membrane material and active principle. An aqueous solution of urea (37.5 wt \%, Sigma-Aldrich) was used as the coating agent. For $\mathrm{pH}$ control, an aqueous solution of sodium hydroxide (25 wt \%, Fisher Chemicals) was used. Isopropyl alcohol (VWR Chemicals) was used to wash the microcapsule solution and acetone (Fisher Chemicals) was used as a solvent for Soxhlet extraction.

2.2. Microencapsulation Process. Microcapsules were prepared by a polycondensation method for which the original batch formulation of melamine-formaldehyde microcapsules was provided by Devan Chemicals and comprises the following steps: emulsification of melamine-formaldehyde prepolymer and Miglyol by moderate homogenization for $4 \mathrm{~min}$; cure of 
microcapsules' membrane in a batch reactor by heating the solution from room temperature to $80{ }^{\circ} \mathrm{C}$ by a ramp-up of 0.6 ${ }^{\circ} \mathrm{C} / \mathrm{min}$ and extending for more $60 \mathrm{~min}$ at a constant temperature; coating by addition of a urea solution and adjusting the microcapsule solution to neutral $\mathrm{pH}$; addition of a few drops of a stabilizer to ensure that phase separation does not occur.

An emulsion of melamine-formaldehyde prepolymer (MFPP) and Miglyol was obtained in the experimental setup shown in Figure 2a using the NETmix reactor at room temperature in two modes: using just one single (first) pass or using recirculation of $4 \mathrm{~min}$ (the emulsification time in the batch formulation) after the first pass. In Figure $2 b$, black filled arrows represent the first emulsion circuit and white filled arrows represent the emulsion recirculation circuit. At the initial feeding of MFPP and Miglyol streams for the emulsion step, the three-way valve is opened toward the waste stream to flush out any water that may remain in the reactor, ensuring that the whole system is filled with reactants only. Afterward, the three-way valve is turned to the product vessel (icon 3 of Figure $2 \mathrm{~b}$ ) to collect the produced emulsion.

The emulsion then undergoes a cure step where the temperature is increased to $80{ }^{\circ} \mathrm{C}$, enabling the formation of the microcapsule shell. This cure step was done by recirculating the emulsion in the NETmix reactor, as shown with gray filled arrows in Figure 2c. Two different cure times were tested in NETmix: $120 \mathrm{~min}$, similar to batch mode, and a shorter period of $30 \mathrm{~min}$. Re $\approx 200$, above the critical Reynolds number, was set for the emulsion and cure steps.

After the recirculation, the NETmix system is drained out and the solution of cured microcapsules is discharged in the product vessel (icon 9 in Figure 2c). Then, the solution is transferred to the batch reactor for the final coating step, which is done by adding an aqueous solution of urea and adjusting the solution $\mathrm{pH}$ to neutral with a sodium hydroxide solution. Finally, a few drops (circa 1 drop per $50 \mathrm{~mL}$ of solution) of a stabilizer are added to the solution to prevent particle coalescence and sedimentation.

2.3. Impregnation of Textile Substrates. The functionalization of cotton fabrics was made by padding, a traditional process of impregnation, using methodologies patented by Devan Chemicals. ${ }^{57,58}$ A nonreactive system, i.e., an impregnation bath with the microcapsule solution and water, was prepared. Fabrics were submerged in this bath and then passed through rollers under a pressure of 4 bar to promote the microcapsule adhesion. The used quantity of dried microcapsule solution was $12 \mathrm{~g} / \mathrm{m}^{2}$ per textile substrate. Fabrics were then dried at $80{ }^{\circ} \mathrm{C}$ for $10 \mathrm{~min}$ to fix the microcapsules.

2.4. Characterization Techniques. 2.4.1. Optical Microscopy (OM). The emulsion and cured and final microcapsules were observed by optical microscopy using a Leica DM 2000 apparatus with different resolutions (100X and $200 \times)$. Sampling of the emulsion and cured microcapsules was done by pipetting through a plastic Pasteur pipette circa 1.5 $\mathrm{mL}$ from the respective product vessel (icons 3 and 9 in Figure 2). These measurements were used to evaluate the behavior of oily droplets and produced microcapsules in terms of size, morphology, and agglomerates.

2.4.2. Scanning Electronic Microscopy (SEM). A desktop scanning electron microscope (Phenom ProX) was used to verify the shell wall integrity, aggregation, morphology, and size of microcapsules. Some droplets of a diluted final solution are placed under a carbon tape. Pins with samples were dried at

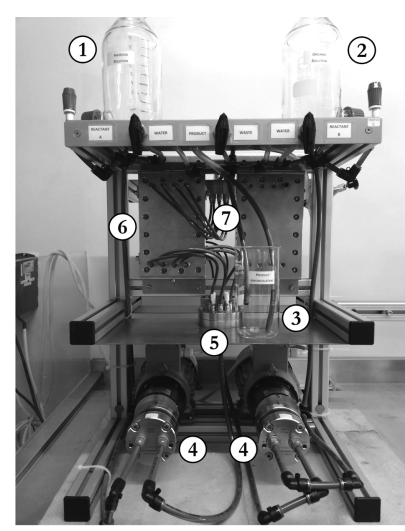

(a)

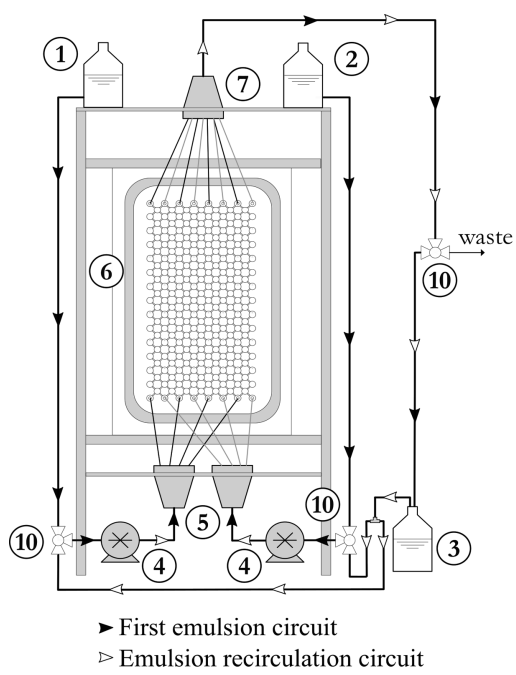

(b)

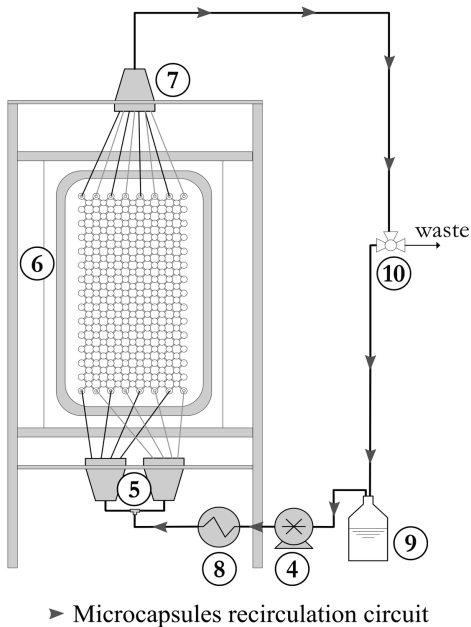

(c)

Figure 2. (a) Experimental setup of Lab-scale NETmix; installation schemes for (b) emulsification step and (c) cure step. Legends: 1 , MFPP vessel; 2, Miglyol vessel; 3, product vessel (emulsion); 4, pumps; 5, distributor; 6, LabNETmix reactor; 7, collector; 8 , inline heater; 9, product vessel (microcapsules); 10, three-way valve.

room temperature for $24 \mathrm{~h}$. SEM was also used to check the microcapsules' impregnation in textiles and verify the dispersion of microcapsules and their behavior after the padding process. 
2.4.3. Laser Diffraction Size Distributions. Size distributions of emulsion droplets and cured and final microcapsules were obtained using a laser diffraction particle size analyzer LS 230 (Beckman Coulter). Sampling was described in Section 2.4.1. The mean values of distributions in volume were determined. The size distributions allow us to infer the range of obtained diameters and the presence of agglomerates of droplets or microcapsules.

Volume size distributions were determined from two measurements of each sample of emulsion droplets and cured and final microcapsules. From each distribution, a value of the mean diameter was obtained. For each sample, an average of mean diameters was calculated as well as its standard deviation, considering two observations of mean diameters.

2.4.4. Shell Thickness Estimative. The membrane thickness, $d_{s}$, is usually estimated by an equation reported by Sliwka for spherical microcapsules of core-shell type ${ }^{59}$ and it was used in this work with a few modifications: different densities of core, $\rho_{\mathcal{c}}$ and shell, $\rho_{s}$, and the actual encapsulated active principle mass, $w_{c}$, were assumed, rather than assuming $100 \%$ encapsulation efficiency. The following relationship was obtained

$$
d_{\mathrm{s}}=\left(r_{\mathrm{m}}-r_{\mathrm{c}}\right)=\left[\left(\frac{w_{\mathrm{s}} \rho_{\mathrm{c}}}{w_{\mathrm{c}} \rho_{\mathrm{s}}}+1\right)^{1 / 3}-1\right] r_{\mathrm{c}}
$$

where $r_{\mathrm{m}}$ is the mean outer radius of the microcapsule, $r_{\mathrm{c}}$ is the radius of the inner core, and $w_{\mathrm{s}}$ is the wall material mass. The densities are $\rho_{\mathrm{c}}=950 \mathrm{~kg} / \mathrm{m}^{3}$ and $\rho_{\mathrm{s}}=1220 \mathrm{~kg} / \mathrm{m}^{3}$.

2.4.5. Solid Content. Solid content estimates the percentage of the mass of microcapsules (shell material and encapsulated oil) in the total mass of the final solution (containing microcapsules, water, and some nonencapsulated oil). The determination of solid content was based on the European norm 827 (British Standards Institution, 2005). ${ }^{60}$ This method allows us to obtain the solid content percentage by the difference in the initial mass of microcapsule solution and the final mass after evaporation of water. A mass of microcapsule solution, $m_{\mathrm{i}}$, is weighed and placed in an oven at $100{ }^{\circ} \mathrm{C}$. After $30 \mathrm{~min}$, the sample is removed from the oven and placed in a desiccator for $15 \mathrm{~min}$. The residual mass is weighed, and the sample is placed again in the oven for $30 \mathrm{~min}$. The process is repeated until the difference of followed weights of residual mass does not exceed $2 \mathrm{mg}$; that is, the residual mass, $m_{\mathfrak{f}}$ is stable. The solid content percentage is obtained by

$$
\mathrm{SC}(\%)=\frac{m_{\mathrm{f}}}{m_{\mathrm{i}}} \times 100
$$

2.4.6. Core Content and Encapsulation Efficiency. Core content is the mass percentage of the active principle, which constitutes the microcapsule core. Soxhlet extraction and Buckner filtration were used to obtain the core content and encapsulation efficiency of the active principle. A known mass of microcapsule solution is filtrated and washed with isopropyl alcohol to remove the nonencapsulated oil dispersed in the solution. The filter cake of microcapsules is then dried in an oven at $100{ }^{\circ} \mathrm{C}$ for $24 \mathrm{~h}$.

For core content quantification, a given mass of dried microcapsules, $m_{\mathrm{mcp}}$ is transferred to a thimble, which is then placed inside a Soxhlet apparatus setup with acetone as the solvent. Extraction occurs for $16 \mathrm{~h}$ with $5 \mathrm{~min}$ cycles.
Afterward, the thimble is removed and dried in the oven at $100{ }^{\circ} \mathrm{C}$ for $24 \mathrm{~h}$ to evaporate the residual solvent. The remaining material in the thimble corresponds to the microcapsule shell and the respective mass, $m_{s}$, is obtained. The core content is determined by

$$
\mathrm{CC}(\%)=\frac{m_{\mathrm{mcp}}-m_{\mathrm{s}}}{m_{\mathrm{mcp}}} \times 100
$$

where $m_{\mathrm{oil}}$ enc $=m_{\mathrm{mcp}}-m_{\mathrm{s}}$ is the mass of the encapsulated oil.

To obtain an estimated value of encapsulation efficiency, the filtrate resulting from the washing step is dried in a $100{ }^{\circ} \mathrm{C}$ oven. From the filtrate, the water is evaporated, and the mass of the free, nonencapsulated oil, $m_{\text {oil, free, }}$ is obtained. The encapsulation efficiency is then given by

$$
\mathrm{EE}(\%)=\frac{m_{\mathrm{oil}, \mathrm{enc}}}{m_{\mathrm{oil}, \text { free }}+m_{\mathrm{oil}, \mathrm{enc}}} \times 100
$$

2.4.7. Thermogravimetric Analysis. Thermogravimetric (TG) analysis was performed on a TG 209 F3 Tarsus by NETZCH. Samples of about 7-8 $\mathrm{mg}$ each were put on aluminum pans and heated at a rate of $10{ }^{\circ} \mathrm{C} / \mathrm{min}$ from room temperature to $600{ }^{\circ} \mathrm{C}$ under a constant $\mathrm{N}_{2}$ flow rate of 50 $\mathrm{mL} / \mathrm{min}$. TG enables the evaluation of the stability of microcapsules by heating through loss mass measurements.

\section{RESULTS AND DISCUSSION}

3.1. Production of Microcapsules. 3.1.1. The Emulsion Step. In the first set of experiments, the emulsions were obtained using a single pass in the NETmix reactor, mixing MFPP and Miglyol, at $R e \approx 200$. The flow rate was measured at $5 \mathrm{~L} / \mathrm{min}$ using a simple bucket and stopwatch method. To evaluate the effect of emulsion recirculation, the second set of experiments was done by placing the resulting emulsion through a recirculation process in the NETmix for a period of $4 \mathrm{~min}$; for this value of $R e$, the passage time in the reactor system is equal to $3.5 \mathrm{~s}$, and thus, this recirculation time corresponds to approximately 70 passes. Figure 3 shows optical microscopy images of the emulsion obtained with a single pass and with recirculation, and Figure 4 shows the respective droplet size distributions.
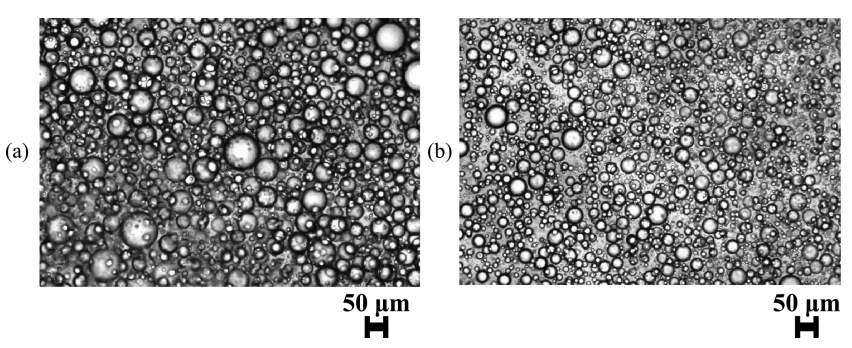

Figure 3. Optical microscopy images of produced emulsion with (a) a single pass and (b) recirculation. Magnification of $100 \times$.

An emulsion containing well-defined spherical droplets with no agglomerates is observed in Figure 3a. A wide range of droplet sizes is observed including large droplets with diameters of circa and above $40 \mu \mathrm{m}$. These diameters are in accordance with the droplet size distributions obtained by laser diffraction (Figure 4). The mean diameter is $44.4 \pm 0.2 \mu \mathrm{m}$, and a bimodal distribution in volume is observed, with a higher intensity peak between 10 and $100 \mu \mathrm{m}$. Even though large diameters are observed, these emulsions remain stable. 


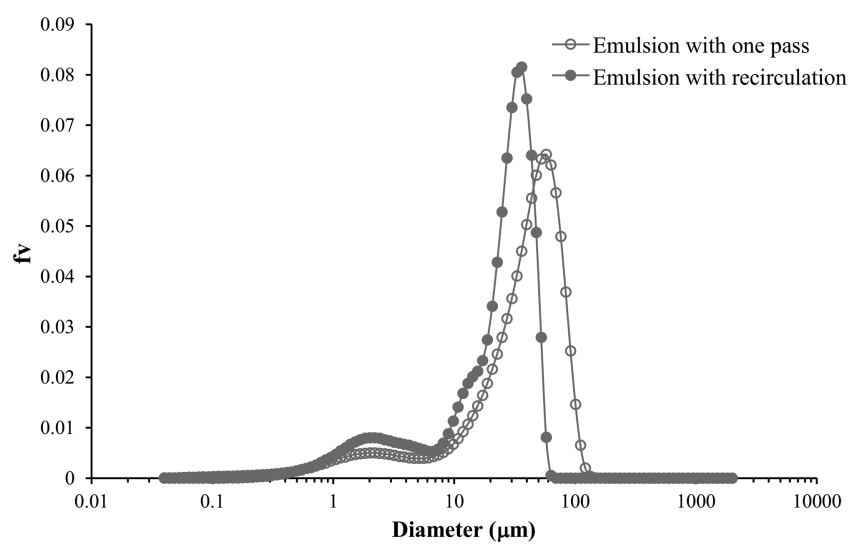

Figure 4. Droplet size distribution of emulsion with a single pass and recirculation.

Figure $3 \mathrm{~b}$ shows the emulsion obtained after recirculation, where again well-defined droplets with uniform and spherical shape and the absence of agglomerates are observed. These emulsions are also stable. However, a decrease in the droplet size is clearly observed, which is confirmed in Figure 4 showing the volume droplet size distributions for selected trials with and without recirculation. The mean droplet diameter here is circa $26.3 \pm 0.2 \mu \mathrm{m}$ and the main peak of the bimodal distribution has a higher intensity and is observed between 20 and $50 \mu \mathrm{m}$.

For all trials, after $4 \mathrm{~min}$ of recirculation, the emulsion identity point has been reached with similar droplet size distributions for all experiments (data not shown) and mean droplet diameters ranging from $23.8 \pm 0.2$ to $32.3 \pm 0.7 \mu \mathrm{m}$, resulting in a mean droplet diameter for all emulsion trials of $27 \pm 3 \mu \mathrm{m}$.

Droplet size is a key parameter in microcapsule textile applications. On the one hand, small microcapsules are easier to fix in fabrics. ${ }^{11,61}$ However, microcapsules with sizes under $10 \mu \mathrm{m}$ will not break easily since they can be entrapped between the fabric fibers, and thus, the active principle release and diffusion process are hindered and the respective performance becomes limited. ${ }^{33}$ On the other hand, microcapsules with sizes above $30-40 \mu \mathrm{m}$ are too fragile and have higher probability of rupture on textiles, releasing the active principle or even breaking during the impregnation process. Also, the larger microcapsules can leave the fabrics after a few washing cycles. $^{11,61}$ Thus, it is generally assumed that the preferred microcapsule sizes for textile applications are between 10 and $40 \mu \mathrm{m},{ }^{33}$ the range obtained in the experiments with recirculation in the NETmix. Therefore, in the following experiments for the cure step, all emulsions were obtained with 4 min recirculation.

3.1.2. The Cure Step. After the emulsion step, the cure step was carried out by recirculating the mixture in the NETmix reactor while increasing the temperature to $80{ }^{\circ} \mathrm{C}$. Figure 5 shows optical images of the microcapsules in solution after each cure step (left-hand side images). The rise in temperature was done in two different ways. Figure 5a shows microcapsules produced with a continuous temperature increase of $0.75{ }^{\circ} \mathrm{C} /$ min to $80{ }^{\circ} \mathrm{C}$ (circa $1 \mathrm{~h}$ and $20 \mathrm{~min}$ ) and then kept constant for another $40 \mathrm{~min}$ for a total period of $2 \mathrm{~h}$. In Figure $5 \mathrm{~b}$, a temperature increase of $4{ }^{\circ} \mathrm{C} / \mathrm{min}$ was set, with circa $15 \mathrm{~min}$ to reach $80{ }^{\circ} \mathrm{C}$ and a further $15 \mathrm{~min}$ at constant temperature for a total of $30 \mathrm{~min}$.

In terms of morphology, all cured microcapsules have the same characteristics. A well-defined spherical shape and the absence of agglomerates were observed. Some cured microcapsules are flat, characteristic of this type of membrane. ${ }^{33,35}$ Microcapsules cured for just $30 \mathrm{~min}$ present similar morphology characteristics as those cured for $120 \mathrm{~min}$. This indicates that the cure time can be reduced using the NETmix reactor, which is noteworthy when compared with a typical cure time of around $150 \mathrm{~min}$ in the traditional batch process.

After curing, the microcapsules undergo the final coating process as described in Section 2.2. These microcapsules, as shown in Figure 5 (right-hand side images), are stable, do not disintegrate, and maintain the same morphology after the cure step until the end of the production process.

(a)

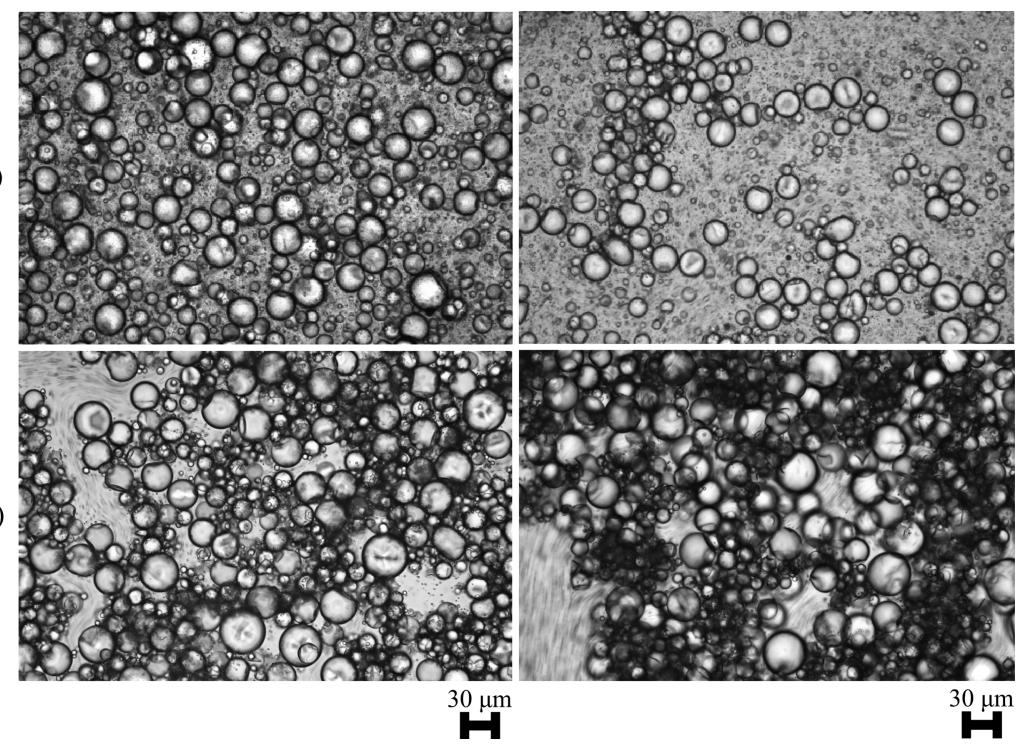

Figure 5. Optical microscopy images of microcapsules after the cure step in NETmix (left) and final solution (right) for a total recirculation period of (a) $2 \mathrm{~h}$ and (b) $30 \mathrm{~min}$. Resolution of $200 \times$. 


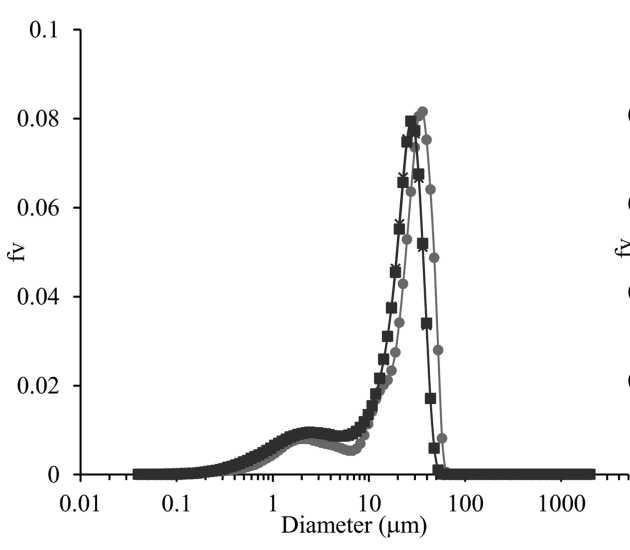

(a)

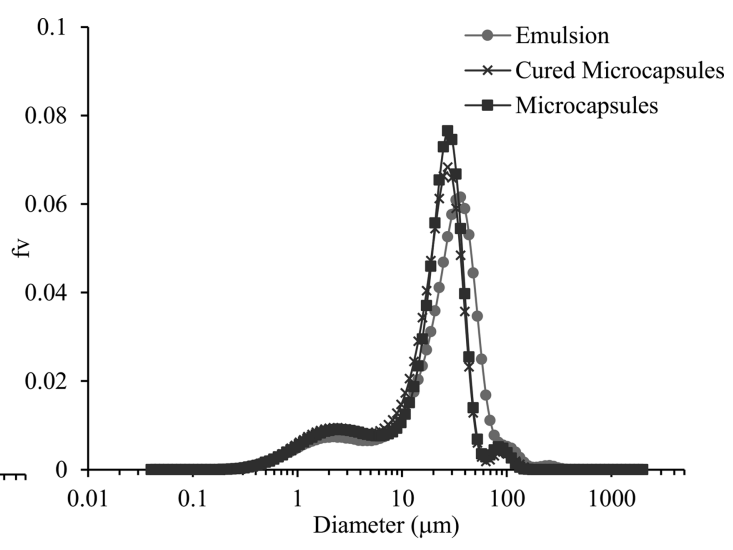

(b)

Figure 6. Volume size distribution for a total recirculation period of (a) $2 \mathrm{~h}$ and (b) $30 \mathrm{~min}$.

Table 1. Measured Mean Volume Diameters, Shell Thickness, Solid and Core Content, and Encapsulation Efficiency ${ }^{a}$

\begin{tabular}{cccccccc}
\multicolumn{7}{c}{ mean diameter $(\mu \mathrm{m})$} \\
circulation & emulsion & cured microcapsules & microcapsules & shell thickness $(\mu \mathrm{m})$ & solid content $(\%)$ & core content $(\%)$ & encapsulation efficiency (\%) \\
$120 \mathrm{~min}$ & 27 & 21 & 20 & 1.3 & 25 & 75 & 75 \\
$30 \mathrm{~min}$ & 32 & 23 & 24 & 1.6 & 25 & 73 & 75 \\
${ }^{a}$ Note that all data correspond to the mean value of two measurements. & & &
\end{tabular}

Figure 6 shows the measured size volume distributions for the emulsion droplets, the cured microcapsules (just after the cure step), and the final microcapsules for selected trials.

The bimodal distribution observed for the emulsion is maintained after the cure and final steps. Distributions of cured and final microcapsules match perfectly, confirming the stability of microcapsules until the end of the process; that is, there is no disintegration or agglomeration. However, the distributions show a slight decrease in size for the cured microcapsules when compared with the emulsion droplet sizes. This is confirmed by the mean volume diameters in Table 1; mean diameters range from $21.1 \pm 0.6$ to $23.2 \pm 0.3 \mu \mathrm{m}$, resulting in a mean droplet diameter for all trials of $22 \pm 1 \mu \mathrm{m}$ for the cured microcapsules and from $20.4 \pm 0.1$ to $24.4 \pm 0.2$ $\mu \mathrm{m}$, resulting in a mean droplet diameter for all trials of $22 \pm 2$ $\mu \mathrm{m}$ for the final microcapsules.

The decrease in size observed between the emulsion droplets and cured microcapsules is slightly lower for the 30 min curing trial. At the beginning of the cure step, the temperature is not high enough to cure the shell. The microcapsule surface only starts to consolidate at a temperature around $50{ }^{\circ} \mathrm{C}$, at which point the membrane is easily detected by $\mathrm{OM}$ (no data are presented). Thus, in the first minutes of recirculation in the cure step, the droplet diameters decrease slightly until the $50{ }^{\circ} \mathrm{C}$ temperature is reached. As previously mentioned, microcapsules obtained with 120 and 30 min curing times were performed at different rates of temperature rise. This means that a temperature of $50{ }^{\circ} \mathrm{C}$ is reached after circa 40 and $8 \mathrm{~min}$ for microcapsules cured for 120 and $30 \mathrm{~min}$, respectively, leading to slightly higher diameters for the $30 \mathrm{~min}$ curing time.

3.1.2.1. Solid Content, Core Content, and Encapsulation Efficiency. Table 1 shows the solid content, core content, and encapsulation efficiency values determined for the different recirculation periods. Similar values were obtained in both cases with maximum uncertainty within $0.2,10$, and $2 \%$ for solid content, core content, and encapsulation efficiency, respectively.

Core content values show that microcapsules are composed of more than $70 \%$ of the oily active principle and the remaining percentage corresponds to the shell material. These values are expected for melamine-formaldehyde-based microcapsules produced by methods similar to polycondensation. The literature reported values of core content around 50$80 \% .^{62-64}$ The high value for the encapsulation efficiency indicates that only a small percentage of oil was not encapsulated.

Table 1 also shows the estimated shell thickness, which is above $1 \mu \mathrm{m}$ for both cases. Microcapsules with $120 \mathrm{~min}$ of circulation show a smaller shell thickness $(1.3 \mu \mathrm{m})$ compared with microcapsules with $30 \mathrm{~min}(1.6 \mu \mathrm{m})$ of circulation, which is expected due to its higher core content (75\% versus $73 \%$ ).

Finally, robustness and stability after washing were confirmed by submitting the dried microcapsules to a new cycle of washing and filtration and verifying that there was no oil in the filtrate.

3.1.2.2. Scanning Electron Microscopy. Figure 7 shows SEM images of the final microcapsules obtained for the two different recirculation periods. Some microcapsule deformation and a few broken microcapsules are observed, but no membrane fragments that could result from the disintegration of microcapsules are detected. In both cases, microcapsules show the same characteristics in terms of morphology: intact microcapsules with spherical shape and smooth membrane. This type of morphology was also reported in previous works for melamine resin microcapsules containing a fragrance for textile impregnation. ${ }^{22,65}$ The sizes of microcapsules match the range of size distributions in volume. Two ranges of diameters are observed: some microcapsules with a size around $5 \mu \mathrm{m}$ and, in a larger percentage, microcapsules with a size around $20 \mu \mathrm{m}$.

3.1.2.3. Thermogravimetric Analysis. TG thermograms of produced microcapsules obtained with different circulation 
(a)
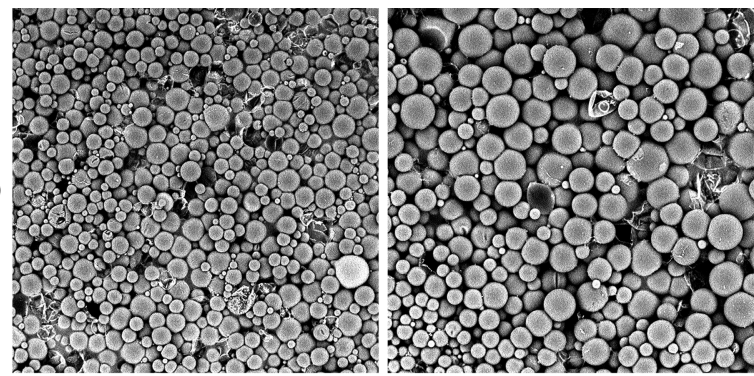

(b)
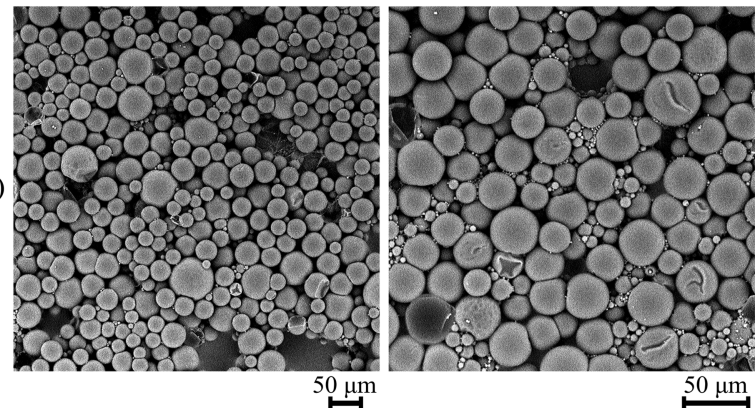

Figure 7. SEM images of microcapsules for a total recirculation period of (a) $2 \mathrm{~h}$ and (b) $30 \mathrm{~min}$. Resolutions of 500x (left) and 1000x (right).

times are shown in Figure 8. In both samples, no substantial water is observed since, until $100{ }^{\circ} \mathrm{C}$, the percentage of weight

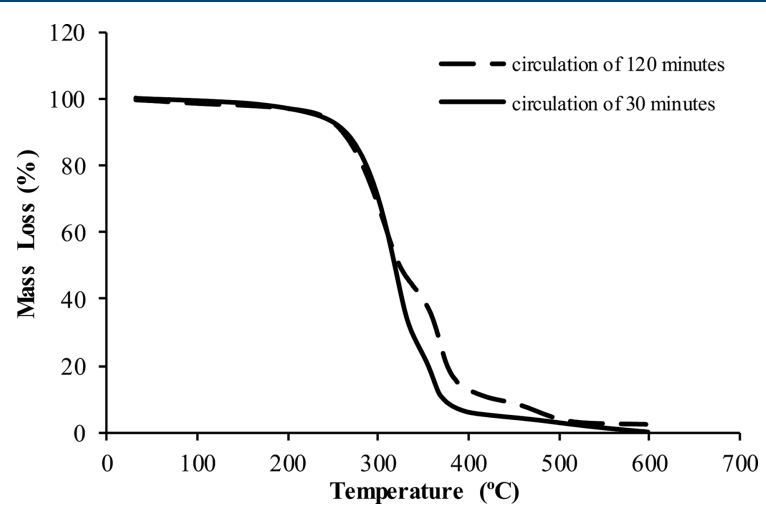

Figure 8. TG thermograms of melamine-formaldehyde microcapsules with curing recirculation of 120 and $30 \mathrm{~min}$.

loss is circa $1 \%$. Melamine resin microcapsules present thermal stability until around $210{ }^{\circ} \mathrm{C}$. This value is in agreement with previously reported data for melamine-formaldehyde microcapsules containing a flame retardant, where the thermal stability was set at around $225^{\circ} \mathrm{C} .{ }^{66}$ Studies of production of nanocapsules of melamine-urea-formaldehyde containing paraffin also show thermal stability around $200{ }^{\circ} \mathrm{C}$. ${ }^{67}$ From 210 to $340{ }^{\circ} \mathrm{C}$, the first stage of considerable weight loss is observed in both samples, resulting from the degradation of melamine-formaldehyde with mass losses of 53 and $71 \%$ for samples with recirculation of 120 and $30 \mathrm{~min}$, respectively. These differences can be attributed to the slightly higher core content obtained in the 120 min circulation samples, which is lower shell content and thus lower weight loss due to melamine-formaldehyde degradation. Above $340{ }^{\circ} \mathrm{C}$, a second stage of the mass loss is observed due to the continuous structural decomposition of melamine-formaldehyde. For the sample with recirculation of $120 \mathrm{~min}$, the second stage is

observed in the range of $340-440{ }^{\circ} \mathrm{C}$, with a mass loss of $34 \%$, while for the sample with recirculation of $30 \mathrm{~min}$, it is in the range up to $400{ }^{\circ} \mathrm{C}$ with a mass loss of $19 \%$. Similar behavior of structural decomposition of melamine-formaldehyde around $340-370{ }^{\circ} \mathrm{C}$ has been reported for microcapsules of melamineformaldehyde containing fragrances and flame retardants. $^{22,66,68}$ Moreover, a study of the thermal behavior of melamine-formaldehyde resin has reported that one of the stages of decomposition occurs in the range of $350-400{ }^{\circ} \mathrm{C} .{ }^{27}$

3.2. Application of Microcapsules to Textiles. The produced microcapsules were impregnated in cotton fabrics at a pressure of 4 bar. After the impregnation process, a piece of fabric was analyzed by SEM to evaluate the integrity of microcapsules after impregnation and adhesion in textiles (Figure 9).

(a)
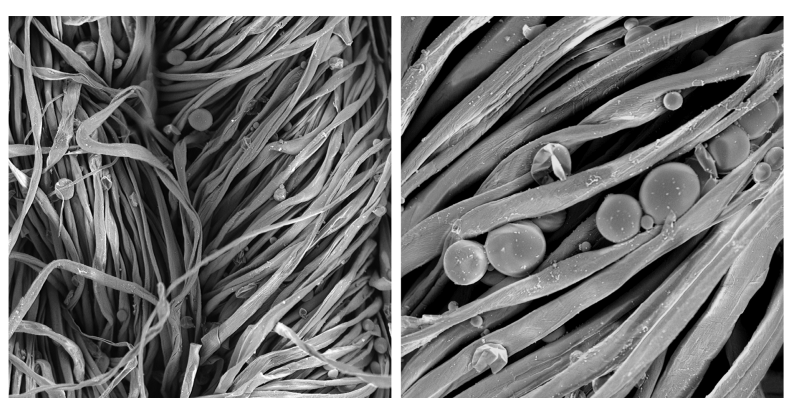

(b)
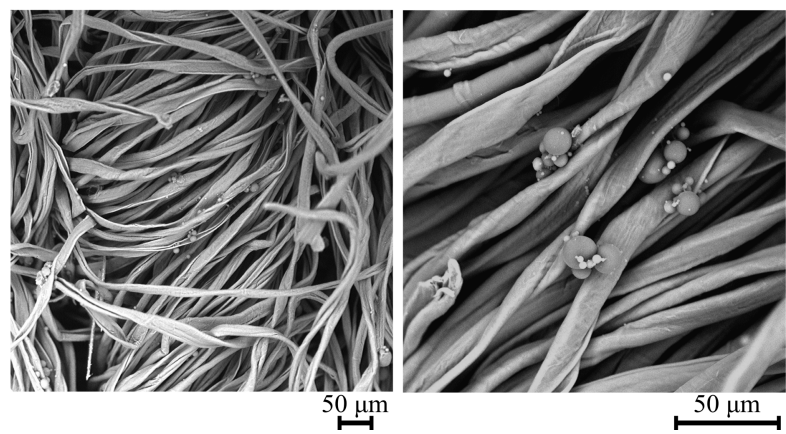

Figure 9. SEM images of impregnated microcapsules in cotton for a total recirculation period of (a) $2 \mathrm{~h}$ and (b) $30 \mathrm{~min}$. Resolutions of $500 \times($ left $)$ and $1000 \times$ (right).

In all cases, the abundance of microcapsules well fixed on the surface of the fibers is apparent. The integrity and shape of the microcapsules were maintained, and the presence of broken microcapsules and membrane fragments is rare.

One known characteristic of this type of melamineformaldehyde microcapsule is the flexible behavior of the shell, which can be observed in Figure 10.

This characteristic is due to viscoelastic behavior at a small deformation, as reported in the literature. ${ }^{22}$ During microcapsule impregnation, the used pressure on roller padding forces some microcapsules to adapt to the fibers and thus prevents the rupture of the membrane. The largest microcapsules (above $30 \mu \mathrm{m}$ ) are located among the fibers instead of at their surface. This is an advantage for textile application since entrapped microcapsules are better protected.

\section{CONCLUSIONS}

In this work, microcapsules of melamine-formaldehyde with an oily active principle, Miglyol, were produced in a continuous mode using the NETmix technology. The emulsion step was 

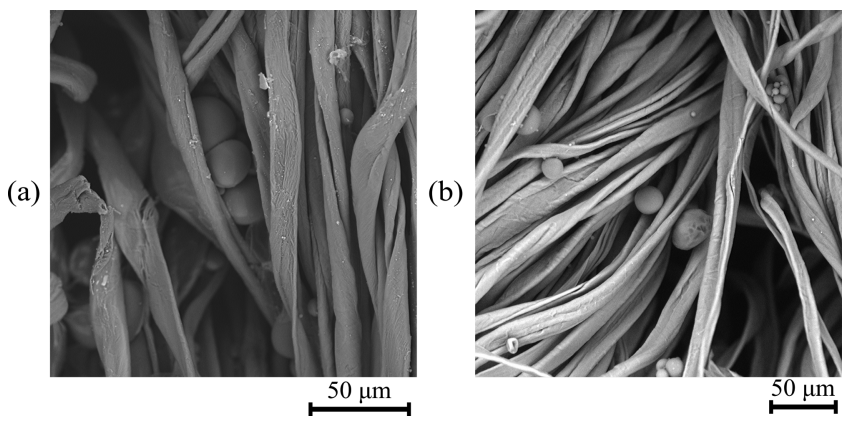

Figure 10. SEM images of impregnated microcapsules in cotton for a total recirculation period of (a) $2 \mathrm{~h}$ and (b) $30 \mathrm{~min}$. Resolutions of $1500 \times(a)$ and $1000 \times$.

performed with a single pass and with recirculation. Both processes produce stable oil-in-water emulsions, which remain stable until the end of the production process. However, recirculation promotes the decrease in the droplet size, from circa 40 to $20 \mu \mathrm{m}$, which is the ideal size range for application on fabrics. The cure step was performed in the NETmix using different recirculation times; in both cases, spherical, resistant, smooth-faced microcapsules, with similar morphology and sizes, were produced. Microcapsules show efficiencies of encapsulation of $75 \%$ and core contents above $60 \%$. Both microcapsules showed thermal stability up to $210{ }^{\circ} \mathrm{C}$. Thus, by performing the cure step in the NETmix, a time reduction from more than $2 \mathrm{~h}$ to $30 \mathrm{~min}$ was achieved. Concerning textile impregnation applications, microcapsules were well fixed to the fibers and present a viscoelastic behavior. Breakability during impregnation was not observed. Thus, the use of the NETmix technology results in stable emulsion production, microcapsules with the desired characteristics, and the reduction of cure time $(80 \%)$ compared to the traditional batch formulation.

This work provides a proof of concept for the capability of NETmix to replace batch processes for microencapsulation. Further work will focus on a different NETmix setup, namely, with smaller chamber and channel sizes and incorporated heat exchanger for easier operation, and on other types of microencapsulation processes. Future work on melamineformaldehyde will focus on process optimization, namely, the effect of recirculation times and Reynolds number on the microcapsule size distributions (uni- or bimodal) and mean diameter. Encapsulation of other active principles, such as vitamin E carried by Miglyol since it is an excellent vehicle for vitamins, and its quantification on textiles will also be carried out.

\section{AUTHOR INFORMATION}

\section{Corresponding Author}

Madalena M. Dias - Laboratory of Separation and Reaction Engineering-Laboratory of Catalysis and Materials (LSRELCM), Faculdade de Engenharia, Universidade do Porto, Porto 4200-465, Portugal; (i) orcid.org/0000-0003-1208-1496; Phone: +351 220413628; Email: dias@fe.up.pt

\section{Authors}

Ana C. G. Moreira - Laboratory of Separation and Reaction Engineering-Laboratory of Catalysis and Materials (LSRELCM), Faculdade de Engenharia, Universidade do Porto, Porto 4200-465, Portugal; ○ orcid.org/0000-0002-5744-7431
Yaidelin A. Manrique - Laboratory of Separation and Reaction Engineering-Laboratory of Catalysis and Materials (LSRELCM), Faculdade de Engenharia, Universidade do Porto, Porto 4200-465, Portugal

Isabel M. Martins - Laboratory of Separation and Reaction Engineering-Laboratory of Catalysis and Materials (LSRELCM), Faculdade de Engenharia, Universidade do Porto, Porto 4200-465, Portugal; Devan Chemicals, Moreira da Maia 4470605, Portugal

Isabel P. Fernandes - Centro de Investigação de Montanha (CIMO), Instituto Politécnico de Bragança, Bragança 5300253, Portugal

Alírio E. Rodrigues - Laboratory of Separation and Reaction Engineering-Laboratory of Catalysis and Materials (LSRELCM), Faculdade de Engenharia, Universidade do Porto, Porto 4200-465, Portugal; @ orcid.org/0000-0002-0715-4761

José C. B. Lopes - Laboratory of Separation and Reaction Engineering-Laboratory of Catalysis and Materials (LSRELCM), Faculdade de Engenharia, Universidade do Porto, Porto 4200-465, Portugal

Complete contact information is available at:

https://pubs.acs.org/10.1021/acs.iecr.0c02656

\section{Notes}

The authors declare no competing financial interest.

\section{ACKNOWLEDGMENTS}

This work was supported by Associate Laboratory LSRE-LCM UID/EQU/50020/2019 funded by national funds through FCT/MCTES (PIDDAC) and Project TexBioPro, POCI-010247-FEDER-003472, funded by FEDER, through COMPETE 2020, under PT2020.

\section{REFERENCES}

(1) Moreira, A. C. G.; Martins, I. M.; Fernandes, I.; Barreiro, M. F.; Rodrigues, A. E. Microencapsulation of red and white thyme oil in poly(lactic-co-glycolic) acid: Assessment of encapsulation efficiency and antimicrobial capacity of the produced microcapsules. Can. J. Chem. Eng. 2016, 94, 469-475.

(2) Dubey, R.; Shami, T. C.; Rao, K. U. B. Microencapsulation Technology and Applications. Def. Sci. J. 2009, 59, 82-95.

(3) Comunian, T. A.; Chaves, I. E.; Thomazini, M.; Moraes, I. C. F.; Ferro-Furtado, R.; de Castro, I. A.; Favaro-Trindade, C. S. Development of functional yogurt containing free and encapsulated echium oil, phytosterol and sinapic acid. Food Chem. 2017, 237, 948956.

(4) Avellone, G.; Salvo, A.; Costa, R.; Saija, E.; Bongiorno, D.; Di Stefano, V.; Calabrese, G.; Dugo, G. Investigation on the influence of spray-drying technology on the quality of Sicilian Nero d'Avola wines. Food Chem. 2018, 240, 222-230.

(5) Choi, D. H.; Park, C. H.; Kim, I. H.; Chun, H. J.; Park, K.; Han, D. K. Fabrication of core-shell microcapsules using PLGA and alginate for dual growth factor delivery system. J. Controlled Release 2010, 147, 193-201.

(6) Oliveira, B. F.; Santana, M. H. A.; Ré, M. I. Spray-Dried Chitosan Microspheres as a pDNA Carrier. Drying Technol. 2006, 24, 373-382.

(7) De Oliveira, J. L.; Campos, E. V. R.; Bakshi, M.; Abhilash, P. C.; Fraceto, L. F. Application of nanotechnology for the encapsulation of botanical insecticides for sustainable agriculture: Prospects and promises. Biotechnol. Adv. 2014, 32, 1550-1561.

(8) Martins, I. M.; Barreiro, M. F.; Coelho, M.; Rodrigues, A. E. Microencapsulation of essential oils with biodegradable polymeric carriers for cosmetic applications. Chem. Eng. J. 2014, 245, 191-200. 
(9) Carvalho, I. T.; Estevinho, B. N.; Santos, L. Application of microencapsulated essential oils in cosmetic and personal healthcare products - a review. Int. J. Cosmet. Sci. 2016, 38, 109-119.

(10) Rodrigues, S. N.; Fernandes, I.; Martins, I. M.; Mata, V. G.; Barreiro, F.; Rodrigues, A. E. Microencapsulation of Limonene for Textile Application. Ind. Eng. Chem. Res. 2008, 47, 4142-4147.

(11) Sharkawy, A.; Fernandes, I. P.; Barreiro, M. F.; Rodrigues, A. E.; Shoeib, T. Aroma-Loaded Microcapsules with Antibacterial Activity for Eco-Friendly Textile Application: Synthesis, Characterization, Release, and Green Grafting. Ind. Eng. Chem. Res. 2017, 56, 55165526.

(12) Specos, M. M. M.; García, J. J.; Tornesello, J.; Marino, P.; Vecchia, M. D.; Tesoriero, M. V. D.; Hermida, L. G. Microencapsulated citronella oil for mosquito repellent finishing of cotton textiles. Trans. R. Soc. Trop. Med. Hyg. 2010, 104, 653-658.

(13) Martí, M.; Martínez, V.; Carreras, N.; Alonso, C.; Lis, M. J.; Parra, J. L.; Coderch, L. Textiles with gallic acid microspheres: in vitro release characteristics. J. Microencapsulation 2014, 31, 535-541.

(14) Rodrigues, S. N.; Martins, I. M.; Fernandes, I. P.; Gomes, P. B.; Mata, V. G.; Barreiro, M. F.; Rodrigues, A. E. Scentfashion ${ }^{\circledR}$ : Microencapsulated perfumes for textile application. Chem. Eng. J. 2009, 149, 463-472.

(15) Devan. Bringing textiles to life. https://devan.net/(accessed 18 July 2019).

(16) Yao, G. P.; Zheng, J. H. Application of Vitamin E Microcapsules on Textiles. Adv. Mater. Res. 2012, 441, 261-265.

(17) Yao, G. P.; Zheng, J. H.; Chen, H. F. Preparation and Application of VE Microcapsules with Polyurethane Shell for SkinCare Textiles. Adv. Mater. Res. 2011, 331, 402-406.

(18) Son, K.; Yoo, D. I.; Shin, Y. Fixation of vitamin E microcapsules on dyed cotton fabrics. Chem. Eng. J. 2014, 239, 284-289.

(19) Mahjour, M.; Mauser, B. E.; Rashidbaigi, Z. A.; Fawzi, M. B. Effects of propylene glycol diesters of caprylic and capric acids (Miglyol ${ }^{\circledR}$ 840) and ethanol binary systems on in vitro skin permeation of drugs. Int. J. Pharm. 1993, 95, 161-169.

(20) Jaworska, M.; Sikora, E.; Ogonowski, J. The influence of glicerides oil phase on $\mathrm{O} / \mathrm{W}$ nanoemulsion formation by pic method. Period. Polytech., Chem. Eng. 2014, 58, 43-48.

(21) Cheng, S. Y.; Yuen, C. W. M.; Kan, C. W.; Cheuk, K. K. L. Development of Cosmetic Textiles Using Microencapsulation Technology. Res. J. Text. Apparel. 2008, 12, 41-51.

(22) Elesini, U. S.; Švarc, J.; Sumiga, B.; Urbas, R. Melamine formaldehyde microcapsules with fragrance core material: Preparation, properties, and end use. Text. Res. J. 2016, 87, 2435-2448.

(23) Sánchez, L.; Lacasa, E.; Carmona, M.; Rodríguez, J. F.; Sánchez, P. Applying an Experimental Design to Improve the Characteristics of Microcapsules Containing Phase Change Materials for Fabric Uses. Ind. Eng. Chem. Res. 2008, 47, 9783-9790.

(24) Martins, I. M.; Rodrigues, S. N.; Barreiro, M. F.; Rodrigues, A. E. Polylactide-Based Thyme Oil Microcapsules Production: Evaluation of Surfactants. Ind. Eng. Chem. Res. 2011, 50, 898-904.

(25) Martins, I. M.; Rodrigues, S. N.; Barreiro, F.; Rodrigues, A. E. Microencapsulation of thyme oil by coacervation. J. Microencapsulation 2009, 26, 667-675.

(26) Severino, P.; Szymanski, M.; Favaro, M.; Azzoni, A. R.; Chaud, M. V.; Santana, M. H. A.; Silva, A. M.; Souto, E. B. Development and characterization of a cationic lipid nanocarrier as non-viral vector for gene therapy. Eur. J. Pharm. Sci. 2015, 66, 78-82.

(27) Merline, D. J.; Vukusic, S.; Abdala, A. A. Melamine formaldehyde: curing studies and reaction mechanism. Polym. J. 2013, 45, 413-419.

(28) Benita, S. In Microencapsulation Methods and Industrial Applications, 2nd; Taylor; Francis; Eds; Drugs and the pharmaceutical sciences; CRC Press: Boca Raton, FL, USA, 2006; 158, 152-155.

(29) Heusch, R. Emulsions. In Ullmann's Encyclopedia of Industrial Chemistry; Wiley-VCH: Weinheim, Germany, 2005; 1-40.

(30) Cerveró, J. M.; Nogareda, J.; del Valle, E. M. M.; Galán, M. A. Development of a technology to produce monodispersed microparticles based on the formation of drops from viscous non-
Newtonian liquids sprayed through a fan jet nozzle. Chem. Eng. J. 2011, 174, 699-708.

(31) Li, M.; Rouaud, O.; Poncelet, D. Microencapsulation by solvent evaporation: state of the art for process engineering approaches. Int. J. Pharm. 2008, 363, 26-39.

(32) Park, S.-J.; Shin, Y.-S.; Lee, J.-R. Preparation and Characterization of Microcapsules Containing Lemon Oil. J. Colloid Interface Sci. 2001, 241, 502-508.

(33) Bône, S.; Vautrin, C.; Barbesant, V.; Truchon, S.; Harrison, I.; Geffroy, C. Microencapsulated Fragrances in Melamine Formaldehyde Resins. Chimia 2011, 65, 177-181.

(34) Hwang, J.-S.; Kim, J.-N.; Wee, Y.-J.; Yun, J.-S.; Jang, H.-G.; Kim, S.-H.; Ryu, H.-W. Preparation and Characterization of Melamine-Formaldehyde Resin Microcapsules Containing Fragrant Oil. Biotechnol. Bioprocess Eng. 2006, 11, 332-336.

(35) Lee, H. Y.; Lee, S. J.; Cheong, I. W.; Kim, J. H. Microencapsulation of fragrant oil via in situ polymerization: effects of $\mathrm{pH}$ and melamine-formaldehyde molar ratio. J. Microencapsulation 2002, 19, 559-569.

(36) Chu, L.-Y.; Utada, A. S.; Shah, R. K.; Kim, J.-W.; Weitz, D. A. Controllable Monodisperse Multiple Emulsions. Am. Ethnol. 2007, $119,9128-9132$

(37) Othman, R.; Vladisavljević, G. T.; Nagy, Z. K. Preparation of biodegradable polymeric nanoparticles for pharmaceutical applications using glass capillary microfluidics. Chem. Eng. Sci. 2015, 137, 119-130.

(38) Souza, L.; Al-Tabbaa, A. Microfluidic fabrication of microcapsules tailored for self-healing in cementitious materials. Constr. Build. Mater. 2018, 184, 713-722.

(39) Zhao, C.-X.; Middelberg, A. P. J. Microfluidic Mass-Transfer Control for the Simple Formation of Complex Multiple Emulsions. Angew. Chem., Int. Ed. 2009, 48, 7208-7211.

(40) Okushima, S.; Nisisako, T.; Torii, T.; Higuchi, T. Controlled Production of Monodisperse Double Emulsions by Two-Step Droplet Breakup in Microfluidic Devices. Langmuir 2004, 20, 9905-9908.

(41) Ekanem, E. E.; Zhang, Z.; Vladisavljevic, G. T. Facile microfluidic production of composite polymer core-shell microcapsules and crescent-shaped microparticles. J. Colloid Interface Sci. 2017, 498, 387-394.

(42) Polenz, I.; Weitz, D. A.; Baret, J.-C. Polyurea microcapsules in microfluidics: surfactant control of soft membranes. Langmuir 2015, 31, 1127-1134.

(43) Vladisavljević, G. T.; Kobayashi, I.; Nakajima, M. Production of uniform droplets using membrane, microchannel and microfluidic emulsification devices. Microfluid. Nanofluid. 2012, 13, 151-178.

(44) Fontana, F.; Ferreira, M. P. A.; Correia, A.; Hirvonen, J.; Santos, H. A. Microfluidics as a cutting-edge technique for drug delivery applications. J. Drug Delivery Sci. Technol. 2016, 34, 76-87.

(45) Kang, K.-K.; Lee, B.; Lee, C.-S. Microfluidic approaches for the design of functional materials. Microelectron. Eng. 2018, 199, 1-15.

(46) Lopes, J.C.B.; Laranjeira, P. E. M. D. S. D. C.; Dias, M. M. G. Q.; Martins, A. A. A. Network mixer and related mixing process. EU Patent 1720643, 2006.

(47) Laranjeira, P. E.; Martins, A. A.; Lopes, J. C. B.; Dias, M. M. NETmix®, a new type of static mixer: Modeling, simulation, macromixing, and micromixing characterization. AIChE J. 2009, 55, $2226-2243$

(48) Laranjeira, P. E.; Martins, A. A.; Nunes, M. I.; Lopes, J. C. B.; Dias, M. M. NETmix ${ }^{\circledR}$, a new type of static mixer: Experimental characterization and model validation. AIChE J. 2011, 57, 10201032.

(49) Costa, M. F.; Fonte, C. M.; Dias, M. M.; Lopes, J. C. B. Heat transfer performance of NETmix - A novel micro-meso structured mixer and reactor. AIChE J. 2017, 63, 2496-2508.

(50) Gomes, P. J.; Silva, V. M. T. M.; Quadros, P. A.; Dias, M. M.; Lopes, J. C. B. A Highly Reproducible Continuous Process for Hydroxyapatite Nanoparticles Synthesis. J. Nanosci. Nanotechnol. 2009, 9, 3387-3395. 
(51) Silva, V. M. T. M.; Quadros, P. A.; Laranjeira, P. E. M. S. C.; Dias, M. M.; Lopes, J. C. B. A Novel Continuous Industrial Process for Producing Hydroxyapatite Nanoparticles. J. Dispersion Sci. Technol. 2008, 29, 542-547.

(52) Ruphuy, G.; Weide, T.; Lopes, J. C. B.; Dias, M. M.; Barreiro, M. F. Preparation of nano-hydroxyapatite/chitosan aqueous dispersions: From lab scale to continuous production using an innovative static mixer. Carbohydr. Polym. 2018, 202, 20-28.

(53) Lima, M. J.; Silva, C. G.; Silva, A. M. T.; Lopes, J. C. B.; Dias, M. M.; Faria, J. L. Homogeneous and heterogeneous photo-Fenton degradation of antibiotics using an innovative static mixer photoreactor. Chem. Eng. J. 2017, 310, 342-351.

(54) Fonte, C. M.; Leblebici, M. E.; Dias, M. M.; Lopes, J. C. B. The NETmix reactor: Pressure drop measurements and 3D CFD modeling. Chem. Eng. Res. Des. 2013, 91, 2250-2258.

(55) Petrusic, S.; Koncar, V. Controlled release of active agents from microcapsules embedded in textile structures. In Smart Textiles and Their Applications; Koncar, V.; Woodhead Publishing Series in Textiles; Elsevier BV: Cambridge, UK, 2016; 178, 89-114.

(56) Walker, R. M.; Gumus, C. E.; Decker, E. A.; McClements, D. J. Improvements in the formation and stability of fish oil-in-water nanoemulsions using carrier oils: MCT, thyme oil, \& lemon oil. J. Food Eng. 2017, 211, 60-68.

(57) Gomes, J .I. N. R.; Vieira, R. M. M. V.; Barros, S. M. P. C. Microcapsules with functional reactive groups for binding to fibers and process of application and fixation. US Patent 91211806, 2013.

(58) Chattopadhyay, S.; Moeller, M.; Keul, H.; Durka, M.; Budzynski, J. Textile Treatment Compounds and compositions. US Patent 9493475B2, 2016.

(59) Sliwka, W. Microencapsulation. Angew. Chem. Int. Ed. Engl. $1975,14,539-550$.

(60) British Standards Institution. Adhesives - Determination of conventional solids content and constant mass solids content (BS EN 827:2005); British Standards Institution: 2005.

(61) Monllor, P.; Capablanca, L.; Gisbert, J.; Díaz, P.; Montava, I.; Bonet, Á. Improvement of Microcapsule Adhesion to Fabrics. Text. Res. J. 2009, 80, 631-635.

(62) Tong, X.-M.; Zhang, T.; Yang, M.-Z.; Zhang, Q. Preparation and characterization of novel melamine modified poly(urea-formaldehyde) self-repairing microcapsules. Colloids Surf., A 2010, 371, 91-97.

(63) Ullah, H.; Azizli, K.; Man, Z. B.; Ismail, M. B. C. Synthesis and Characterization of Urea-formaldehyde Microcapsules Containing Functionalized Polydimethylsiloxanes. Procedia Eng. 2016, 148, 168175.

(64) Ollier, R. P.; Alvarez, V. A. Synthesis of epoxy-loaded poly(melamine-formaldehyde) microcapsules: Effect of $\mathrm{pH}$ regulation method and emulsifier selection. Colloids Surf., A 2017, 520, 872882.

(65) Hong, K.; Park, S. Melamine resin microcapsules containing fragrant oil: synthesis and characterization. Mater. Chem. Phys. 1999, $58,128-131$.

(66) Salaün, F.; Vroman, I. Influence of core materials on thermal properties of melamine-formaldehyde microcapsules. Eur. Polym. J. 2008, 44, 849-860.

(67) Han, S.; Lyu, S.; Wang, S.; Fu, F. High-intensity ultrasound assisted manufacturing of melamine-urea-formaldehyde/paraffin nanocapsules. Colloids Surf., A 2019, 568, 75-83.

(68) Fei, X.; Zhao, H.; Zhang, B.; Cao, L.; Yu, M.; Zhou, J.; Yu, L. Microencapsulation mechanism and size control of fragrance microcapsules with melamine resin shell. Colloids Surf., A 2015, 469, 300-306. 